\title{
МЕЖДУНАРОДНЫЙ ОПЫТ ПРИМЕНЕНИЯ ЭКОЛОГИЧЕСКИХ КРИТЕРИЕВ В ГОСУДАРСТВЕННОЙ ЗАКУПОЧНОЙ ПРАКТИКЕ
}

\section{(c) 2019 Липина Светлана Артуровна}

доктор экономических наук, профессор, заведующая научно-исследовательской лаборатории «Исследования актуальных вопросов развития конкурентной политики и государственного заказа

в российской экономике» Центра развития конкурентной политики и государственного заказа Российской академии народного хозяйства и государственной службы при Президенте Российской Федерации, руководитель Отделения - Заместитель Председателя Совета по изучению производительных сил Всероссийской академии внешней торговли Министерства экономического развития Российской Федерации по проблемам размещения производительных сил и региональной экономике E-mail: s.lipina@mail.ru

\section{(c) 2019 Агапова Елена Викторовна}

кандидат экономических наук, доцент, ведущий научный сотрудник научно-исследовательской лаборатории «Исследования актуальных вопросов развития конкурентной политики и государственного заказа в российской экономике» Центра развития конкурентной политики и государственного заказа Российской академии народного хозяйства и государственной службы при Президенте Российской Федерации, директор Центра развития конкурентной политики и государственного заказа Российской академии народного хозяйства и государственной службы при

Президенте Российской Федерации

E-mail: agapova@ranepa.ru.

\section{(c) 2019 Липина Александра Валерьевна}

научный сотрудник научно-исследовательской лаборатории «Исследования актуальных вопросов развития конкурентной политики и государственного заказа в российской экономике» Центра развития конкурентной политики и государственного заказа Российской академии народного хозяйства и государственной службы при Президенте Российской Федерации, ассистент кафедры геологии и маркшейдерского дела Горного института Национального исследовательского техноло-

гического университета «МИСиС»

E-mail: a.v.lipina@mail.ru

Одной из сфер «зеленой» экономики, где мировые лидеры накопили практический опыт управления процессом расходования бюджетных средств на государственном уровне, является область «зеленых» государственных закупок (Green Public Procurement, GPP). В статье дается анализ международного опыта применения на практике инструмента экономического развития - «зелёных» государственных закупок, который выполняет функцию поддержки экономической устойчивости в целях экологически ориентированного развития. На сегодняшний день многие развитые страны уже сравнительно далеко продвинулись в деле формализации требований к системе экологического регулирования государственных заказов. Такая политика «зеленых» закупок важна для инновационного развития, с обязательством выбора приоритетных направлений, с внедрением идей осуществления поставок только сертифицированной продукции.

Ключевые слова: «зелёная» экономика, «зелёные» закупки, экологическое развитие, устойчивое развитие, социально-экономическое развитие.

Международный опыт закупок государства в той или иной степени частично раскрыт многими учеными $[4,5]$, где закупки государства на международном уровне исследуются как форма мировой торговли, когда услуга или товар определяются технико-экономическими характери- стиками и параметрами, исходя из задач покупателя.

Как обнаруживает анализ товаров, продвигаемых в рамках концепции «зеленых» закупок в развитых странах, эта продукция легко поддается качественной оценке и включает эколо- 
гически сертифицированные товары и услуги (энергоэффективную компьютерную технику, офисную мебель из экологичных материалов, бумагу из вторсырья, автомобили с электроприводом, экологически дружественный общественный транспорт, а также электроэнергию, получаемую из возобновляемых источников).

В течение последних двадцати лет идет активное реформирование национальной политики по экологизации экономики и рыночному стимулированию экологически чистой продукции. Переломным моментом для внедрения концепции экологически безопасных государственных закупок стала прошедшая в 1992 году в Рио-де-Жанейро Конференция ООН по окружающей среде и развитию [6]. На этой конференции более 178 стран приняли Декларацию, которая призывала не только к экологической ориентированности и устойчивому развитию государства, но и к принятию конкретных мер, ориентированных на использование покупательной способности государств в целях улучшения экологических показателей.

Сегодняшние страны «зелёной семерки» уже с 1995 года стали применять так называемые экологические закупки, внедрили у себя элементы системы зелёного государственного заказа (минимизация негативного влияния на окружающую среду). В 2002 году были приняты и рекомендации по экокритериям государственных закупок [7], устанавливающие экостандарты системы государственных закупок и приобретение «зеленых» продуктов и услуг. Рекомендуемые критерии [8] минимизируют воздействие внешнюю среду, распределяясь по множеству этапов продуктового жизненного цикла, включая экологические издержки на сырье, транспортировку, хранение и утилизацию продукта, международные организации поддерживают инновационные компании $[9,10,11]$.

Приводя в пример деятельность организации ОЭСР и «Программу ООН по окружающей среде», а также делая анализ внедрения «зеленых» закупок во многих секторах экономики зарубежных стран, авторы [12, 13, 14, 15] подчеркивают, что инвестиции в инновационные и экологически чистые технологии для производства «зеленой» продукции обеспечивают баланс трех основных факторов устойчивого развития: социальных, экономических и экологических, так как позволяет государству использовать бюджетные расходы на «зеленые» государственные закупки для социальных целей.

Так как экологические критерии становятся обязательной нормой в законах, регулирующих государственные закупки, то для помощи странам в имплементации «зеленой» повестки в государственные закупки был подготовлен доклад о мерах внедрения основных принципов:

- обеспечение конкурентной среды;

- о предотвращении проявлений коррупции;

- о развитии добросовестной конкуренции.

Эти принципы и экологические критерии по программе «зеленых» государственных закупок должны быть приведены в соответствие с принятой в EC директиве RoHS по ограничению содержания вредных веществ (Restriction of Hazardous Substances Directive) и регламентом CLP.

Учитывая положительные примеры систем «зеленых» закупок, и в коммерческом секторе, и в отдельных государственных компаниях в 2011 году Организацией по экономическому сотрудничеству и развитию (ОЭСР) определены следующие препятствия, преграждающие путь к покупкам экологически чистых услуг и товаров:

- стоимость экологически чистых продуктов выше;

- информации о таких продуктах и услугах явно недостаточно;

- недостаточно стимулов для осуществления «зеленых» проектов;

- партнеры-поставщики отсутствуют в достаточном количестве.

Анализ же самой системы «зеленого» государственного заказа, основанной на закупках услуг и продукции, которые бы минимизировали негативное воздействие при их использовании на окружающую среду, показывает, что в Евросоюзе экологическая ориентированность госзакупок нормативно закреплена, а их основа заложена в международных стандартах серии ISO 14020.

В ходе исследования выявлено, что в разных странах наблюдается вариативность сфер применения «зеленых» закупок, а также и существуют разные подходы к нормативно-правовому регулированию.

Мировая практика показывает, что управление системой государственных закупок включает в себя правовые и экологические вопросы.

Изучая и анализируя опыт стран, социальное и экономическое развитие которых находится на разных уровнях, по применению в практике 
государственных закупок экологически чистых закупок (GPP), исследователи пришли к выводу, что в большинстве стран на законодательном уровне закреплены инициативы добровольной экологической сертификации, то есть на государственном уровне сформирована система «зеленых» государственных закупок.

Однако, обзор литературы по анализу зарубежного опыта управленческих решений в части экологизации экономики и управления «зелеными» государственными закупками показывает, что ряд авторов $[17,16,18]$ придерживаются мнения, что сфера государственных «зеленых» закупок страдает отсутствием единой терминологии, то есть любая страна или объединение стран, организация или финансовый институт могут пользоваться собственной терминологией в сфере «зеленых» закупок. В такой ситуации осложняется поиск и применение общих практик при организации системы государственных закупок» [19].

Для построения ясного и хорошо слаженного подхода к регулирующим инструментам «зеленых» закупок, Совет ЕС и Европейский Парламент приняли две Директивы, 2004/18/EC [20] и 2004/17/EC [21], которые содержат четкие рекомендации по внесению экологических требований в контракты в процессе их заключения. Это обеспечило объективными и профессиональными требованиями и критериями процедуры закупок и инспекционный контроль над сертифицированным продуктом.

Предпринятые Директивами 2004/18/EC и 2004/17/ЕС, законодательные меры обеспечивают методическими рекомендациями все процедуры заключения контрактов и позволяют [20]:

- вносить экологические требования (статья 23 (3) б) в разрабатываемые технические условия;

- применять эко-лейблы, или экологические товарные знаки (статья 23 (6));

- устанавливать экологические и социальные условия при исполнении контрактов (статья 26);

- выдвигать к поставщикам требования информации, свидетельствующей и выполнении ими экологических обязательств (статья 27);

- при выборе победителя применять критерии, в основе которых лежат экологические характеристики (статья 53).

В результате положительный эффект от зеленых» закупок дает мотивацию для расширения деятельности малых и средних компаний, которыми может быть извлечена выгода при экологических закупках, вследствие получаемой ими возможности нахождения новых рынков сбыта для своих продуктов и инновационных решений.

Кроме того Еврокомиссия призвала государства ЕС выработать конкретные план по развитию и внедрению экологически чистых закупок в государственные закупки, для чего было необходимо провести анализ сложившейся экологической ситуации в странах и регионе в целом, наметить конкретные цели по улучшению, определить мероприятия для «озеленения» своих государственных закупок, кроме того эти общедоступные национальные планы (НПД) [14] должны содержать и амбициозные цели на ближайшие три года.

На основании этих Директив (2004/18/EC и 2004/17/EC), все страны ЕС разработали собственные национальные планы по «озеленению» своих экономик, что явилось политическим импульсом по управлению процессом реализации многих инновационных индикаторов развития, в том числе и экологических государственных закупок.

При анализе исследований (Fox, Ward and Howard, 2002; Steurer et al., 2007) [15] и опыта внедрения экологических аспектов в государственные закупки можно выделить следующие наиболее действенные инструменты внедрения «зеленых» закупок и поддерживающих их разработок:

- информационные инструменты (проведение различных тренингов, разработка государственными институтами руководств по созданию, внедрению и обеспечение доступа бизнеса разных уровней к информационным ресурсам отчетам, сайтам; проведение кампаний, предусматривающих награждение лучших участников);

- применение инструментов партнерства (заключение соглашение, создание профессиональных сетей, ведение диалога, создание ГЧП);

- применение финансовых и экономических инструментов (инвестиции, гранты, субсидии);

- применение правовых инструментов (принятие указов, законов, руководств, резолюций);

- гибридные инструменты (стратегии и планы действий).

Эти инструменты многократно апробиро- 
ваны на практике в разных странах и регионах, и их можно использовать, адаптируя к российским условиям, для этого приоритеты «зеленых» экологичных государственных закупок должны быть вписаны в общие стратегии развития государства.

Для организации методической помощи в международной практике применяются различные системы управления закупками, в том числе и «зелеными», в мире. Так международные организации: OECD - Организация экономического сотрудничества и развития (Organization for Economic Cooperation and Development), Всемирный Банк (The World Bank), Европейский банк реконструкции и развития (European Bank for Reconstruction and Development), Сеть государственных закупок PPN (The Public Procurement Network) и другие проводят исследования по улучшению подходов к управлению системами государственных закупок. Обзор методологий [22, 23, 24] этих международных организаций и их анализ демонстрируют, что в основе описанных методик лежат общие принципы и критерии оценки закупочных систем, включающих и процессы регулирования на рынке безопасных товаров и услуг.

Так методики оценки эффективности процедур закупок «зеленых» товаров WB, EBRD очень тщательно проработаны, вносят в процедуры оценок множество экологических критериев, предлагаются варианты и характер описания управления закупочной деятельностью экологических товаров и услуг, носят нормативноправовой характер и очерчивают направления деятельности и детально регулируют проведение качественной и количественной оценки. Методики проведения оценки «зелености» товаров включают основные стержневые показатели экологичности: определение инновационности, разработку критериев оценки и составление на их базе вопросников, перевод этих вопросников в числовые базы данных, начисление на этой основе баллов и последующая оценка.

При этом процесс регулирования на рынке более безопасных товаров и услуг сводится, в основном, к разрешению социальных проблем, для чего разрабатываются соответствующие стратегии внедрения «зеленых» государственных закупок из существующих экологических и социальных целей, когда в социальную справедливость включены такие вопросы, как безопасность, права человека, гендерное равенство, вопросы сокращения бедности и др.

Реализация «зеленых» государственных закупок базируется на разработке универсальных инструментов их внедрения, определении алгоритма внедрения «зеленых» закупок, что предлагается многими международными программами. Так, материалы, разработанные международной программой Прокьюра+, подробно рассматривают универсальные алгоритмы и руководства по внедрению. Больший интерес представляют Procura+ (Руководство, 2007) [2], UNEP (Руководство по внедрению, 2012) [25], в которых обосновываются инструменты и алгоритмы реализации на практике эти действенные программы.

Наиболее интересны и универсальны исследования (Ward and Howard, 2002; Fox, Steurer etal., 2007) [26], которые выделяют и группируют поддерживающие и информационные инструменты внедрения «зеленых» государственных закупок:

- проведение тренингов, создание и обеспечение доступа к информационным ресурсам сайтам, отчетам,

- инструменты партнерства для заключения соглашений, выделены финансовые или экономические инструменты (инвестиции, субсидии, гранты),

- названы нормативно- правовые документы, необходимые для внедрения (законы, указы, резолюции, руководства).

Управленческие решения, связанные с внедрением экологических критериев для государственных закупок большинства зарубежных государств, определяются стратегической политикой на уровне макроэкономики:

- Стратегия устойчивого развития ЕС - СДС (2001-2011) - Принятая странами Европейского союза стратегия устойчивого развития легла в основу разработки национальных стратегий отдельных стран ЕС. Главная цель - сократить воздействие на окружающую среду;

- «Европа 2020: стратегия разумного, устойчивого и всеобъемлющего роста». Главная цель продвижение идеи более целесообразного использования природных ресурсов, улучшения экологической обстановки и конкурентоспособности в экономике.

- Дорожная карта (к ресурсоэффективной Европе)

- Энергия 2020 - Стратегия для конкурентной, устойчивой и безопасной энерге- 
тики - создает «подушку безопасности» для энергопотребления, делая акцент на возобновляемые источники энергии

- Инновационный союз / Эко-инновации План действий - Ecoap - создает стимулы для инноваций в промышленности, предъявляя требования к продукции «устойчивого производства, способствует созданию эко-инноваций путем создания структуры, объединяющей национальные и европейские научно-исследовательские проекты.

Таким образом, сегодня в большинстве стран Евросоюза экологическая ориентированность госзакупок закреплена в законодательстве уровне, а среди инструментов экологической политики «зеленых» законов и нормативноправовых актов имеются и серия методических материалов, в рамках которых и функционирует система «зеленых» закупок товаров и услуг.

Используя методы устойчивых «зеленых» государственных закупок, государства формируют таким образом долгосрочный и высокий спрос в отношении «зеленых» товаров и услуг, что заставляет компании прибегать к более долгосрочным инвестициям в инновации, а производители выигрывают, снижая затраты за счет роста масштабов.

Конкурсная форма закупок подталкивает коммерциализацию «зеленых» услуг и товаров, и создает устойчивый потребительский спрос. Так, использование программ устойчивых госзакупок в Дании, Австрии, Финляндии, Нидерландах, Германии, Великобритании и Швеции, позволило снизить выбросы окиси углерода, связанные с «экологичными» госзакупками, на 25\%.

Таким образом, в экономиках развитых стран хорошо продуманная и стимулирующая функция процедур аукционов и торгов влечет за собой решение ряда задач, которые способствуют формированию новой экономической модели хозяйствовании - переходу к «зеленой» экономике. Внедрение наиболее современных производственных и управленческих технологий и НИОКР, что позволяет добиваться не только более высокого уровня конкурентоспособности продукции, но и рассматривать закупочные системы государства источниками роста национальной экономики.

Экономическая модель «зеленого» роста предлагает различные инструменты для осуществления закупочных процедур (разработка нормативно-правовой базы, планирование, контроль и координация деятельности) см. рис 1.

Государственный заказ по «зеленым» закупкам может использоваться в Российской Федерации как один из элементов системы поддержки экономической и социальной стабильности и инструмент модернизации национальной экономики, что может стать драйвером экономического роста и будет максимально содействовать развитию инновационных отраслей экономики.

На основании вышеизложенного, наиболее интересны и практически выполнимы в современной российской практике следующие элементы зарубежного опыта:

1. Госзакупки «зеленых» товаров и услуг осуществляются централизовано с помощью специализированного государственного органа с последующим распределением в государственные учреждения.

2. Методика конкурсных торгов единая, где используются библиотеки типовых контрактов и банки данных требований к закупаемой продукции.

3. Аудит процесса закупок осуществляется органами (центрами), которые имеют методики

\section{Важнейшие рычаги государственного регулирования} развития «зеленых» государственных закупок

Единая цель. Главная стратегическая цель: удовлетворение потребностей в экологических товарах, работах и услугах

Планирование. Строгая регламентация процедур и противостояние коррупции; планирование обеспечения государственных нужд

Единая методология. Проведение торгов по единой методологии, с использованием библиотеки типовых контрактов

Открытость. Информационная публичная открытость и гласность всех контрактных процессов и их результатов

упрощение законодательства управления и регулирование государственными заказами практика предоставления преференций местным поставщикам и подрядчикам при государственных закупках

Рисунок 1. Основные аспекты международного опыта «зеленых» государственных закупок. 
организации торгов, обеспечения чистой конкуренции, контроля за исполнением контрактов, анализа эффективности обеспечения государственных нужд.

Поэтому для России становится очевидной необходимость регламентации процедур размещения государственного заказа, основанных на принципах концепции так называемых «зеленых» закупок, которые являются наиболее реальным инструментом не только для стимулирования инноваций и разработки новых продуктов с улучшенной экологической эффективностью, но и важнейшей задачей сегодняшнего дня - импортозамещением.

\section{Библиографический список}

1. Федеральный закон от 05.04.2013 № 44-Ф3 «О контрактной системе в сфере закупок товаров, работ, услуг для обеспечения государственных и муниципальных нужд».

2. Руководство по внедрению Устойчивых государственных закупок\\ United Nations Environment Programme. Париж. 2012.- [Электронный ресурс]. Режим доступа: http://ecounion.ru/wp-content/uploads/2014/04/ UNEPImplementationGuidelines_RUS.pdf

3. «Основы государственной политики в области экологического развития Российской Федерации на период до 2030 года» (утв. Президентом РФ 30.04.2012)

4. Снеткова А.В. Международный опыт организации государственных закупок [Электронный ресурс].Режим доступа: http://topknowledge.ru/upravlenie-ekonomikoj/4166-mezhdunarodnyj-opyt-organizatsiigosudarstvennykh-zakupok.html

5. Федеральная контрактная система США. [Электронный ресурс].- Электрон. дан.- Режим доступа: http://zakupki-tendery.ru/articles/item/146

6. Декларация Рио-де-Жанейро по окружающей среде и развитию (Принята в г. Рио-де-Жанейро 14.06.1992) // Действующее международное право. Т. 3.- М.: Московский независимый институт международного права, 1997. С. 687-692. Международное публичное право. Сборник документов. Т. 2.- М.: БЕК, 1996. C. $135-138$.

7. Рекомендации совета по внедрению экологических критериев госзакупок товаров и услуг. Communication from the Commission to the European Parliament, the Council, the European Economic and Social Committee and the Committee of the Regions. Brussels, 16.7.2008. pp. 2-3.

8. Regulation № 106/2008 on a Community energy-efficiency labelling programme for office equipment - Регламент 106/2008/ЕС Европейского парламента и Совета от 15 января 2008 года по программе маркировки энергоэффективности офисного оборудования в ЕС.

9. Brammer S. Walker H. Sustainable Procurement in the Public Sector: An International Comparative Study // International Journal of Operations \& Production Management. 2011. Vol. 31. N. 4. P. 452-476.

10. COM (2001) 264 final. A Sustainable Europe for a Better World: A European Union Strategy for Sustainable Development. 2001. [Электронный ресурс] - Режим доступа: https://eur-lex.europa.eu/LexUriServ/LexUriServ. do?uri=COM:2001:0264: FIN: EN: PDF

11. Naija L., Warren G. Procurement for Sustainable Local Economic Development // International Journal of Public Sector Management. 2012. Vol. 25. N2. P. 133-153.

12. Sylvie Lemmet Sustainable Public Procurement Implementation Guidelines Introducing UNEP’s Approach. UNEP DTIE, 2012

13. Perera O., Chowdhury N., Goswami A. State of Play in Sustainable Public Procurement. International Institute for Sustainable Development (IISD) and The Energy and Resources Institute (TERI). Manitoba. 2007

14. Procurement \& Public-Private Partnerships. Strategic Government Spending for Sustainable Development. International Institute for Sustainable Development. [Электронный ресурс]. - Режим доступа: http://www.iisd. org/Procurement.

15. Fox T., Ward H., Howard B. Public Sector Roles in Strengthening Corporate Social Responsibility: A Baseline Study. The World Bank. 2002. [Электронный ресурс]. - Режим доступа: http://pubs.iied.org/pdfs/16017IIED.

16. Preuss L. Addressing Sustainable Development Th rough Public Procurement: Th e Case Local Government // Supply Chain Management. 2009. Vol. 14. N. 3. P. 213-224.

17. The Impact of Sustainable Public Procurement. UNEP. Paris. 2012. [Электронный ресурс].- Режим доступа: http://www.unep.fr/scp/procurement/docsres/ProjectInfo/StudyonImpactsofSPP.pdf

18. Qiao Y., Wang C. Issues and Challenges in Implementing China's Green Public Procurement Program // Journal of Environmental Protection. 2011. N. 2. P. 1034-1045 
19. Perera O., Morton B., Perfrement T. Life Cycle Costing in Sustainable Public Procurement: A Question of Value. International Institute for Sustainable Development. 2009.

20. Директива 2004/18/ЕС Европейского Парламента и Совета от 31 марта 2004 г. по координации процедур оплаты общественных работ, поставок для общественных целей и общественных сервисных контрактов (Directive 2004/18/EC of the European Parliament and of the Council of 31 March 2004 on the coordination of procedures for the award of public works contracts, public supply contracts and public

21. Директива 2004/17/ЕС Европейского Парламента и Совета от 31 марта 2004 г. по координации процедур закупки для организаций, работающих в области водных ресурсов, энергии, транспорта и почтовых услуг (Directive 2004/17/EC of the European Parliament and of the Council of 31 March 2004 coordinating the procurement procedures of entities operating in the water, energy, transport and postal services sectors). Final Report. United Nation Environmental Program, 2013.

22. Methodology for Assessing Procurement Systems [Электронный ресурс].- Режим доступа: http://www.oecd. org/dac/effectiveness/45181522.pdf

23. Methodology for Assessment of National Procurement Systems (Version 4) July, 172006 [Электронный ресурс].Режим доступа: http://www.oecd.org/development/effectiveness/37390076.pdf

24. OECD (2007), «Central Public Procurement Structures and Capacity in Member States of the European Union», Sigma Papers, No. 40, OECD Publishing. [Электронный ресурс].- Режим доступа: http://dx.doi. org/10.1787/5kml60qdqq0n-en Sustainable Public Procurement: A Global Review Final Report, 2013

25. Development of the National Green Economy Vision in the Russian Federation to Provide the Transition towards Sustainable Consumption and Production (Nov 2011 - March 20) [Электронный ресурс].- Режим доступа: http://www.unrussia.ru/en/agencies/united-nations-environment-programme-unep

26. Public policies on CSR in Europe: Themes, instruments, and regional differences Reinhard Steurer, S. Margula \& A. Martinuzzi [Электронный ресурс].- Режим доступа: http://www.wiso.boku.ac.at/fileadmin/data/H03000/ H73000/H73200/InFER_Discussion_Papers/InFER_DP_12_2_Regional_differences.pdf 